\title{
PENGARUH PENERAPAN PERAN KOMITE AUDIT, PERAN DEWAN PENGAWAS SYARIAH, DAN EFEKTIVITAS PENGENDALIAN INTERN ATAS PELAPORAN KEUANGAN TERHADAP KUALITAS PELAPORAN KEUANGAN
}

\section{(STUDI EMPIRIS PADA BANK SYARIAH DI INDONESIA)}

\section{Rini}

UIN Syarif Hidayatullah Jakarta

Email: rini@uinjkt.ac.id

\begin{abstract}
This study examines the effect of audit committee role, shari'a supervisory board role, and internal control over financial reporting effectiveness, on financial reporting quality. The data is taken by questionnaire from 173 employees (group head, division head, and internal auditor), audit committee members, and shari'a supervisory board members of 33 Islamic banking in Indonesian. Research results that used path analysis, show that a positive correlation exists between audit committee role, shari'a supervisory board role, and internal control over financial reporting effectiveness. There is strongest relationship between shari'a supervisory board role with internal control over financial reporting effectiveness. Furthermore, audit committee role, shari'a supervisory board role, and internal control over financial reporting effectiveness influence financial reporting quality simultaneously. Partially audit committee role, and internal control over financial reporting effectiveness influence financial reporting quality, but statistically shari'a supervisory board role was not significant.
\end{abstract}

Keywords: audit committee role, shari'a supervisory board role, internal control over financial reporting effectiveness, and financial reporting quality.

\section{PENDAHULUAN}

Bank syariah merupakan salah satu bentuk dari lembaga keuangan syariah. Chapra dan Khan (2000) menyatakan bank syariah adalah bank yang menerapkan syariah Islam dalam semua aspek keyakinan dan prakteknya. Pendapat Chapra ini mendukung gambaran hubungan Islam dengan lembaga keuangan yang dinyatakan oleh Antonio (2001).

Saat perbankan konvensional mengalami keterpurukan akibat krisis keuangan global, bank syariah malah mengalami keuntungan yang signifikan, malah diprediksi pertumbuhannya akan meningkat dua kali lipat. Menurut Gubernur Bank Sentral Bahrain Rasheed Mohammed Al Maraj, industri keuangan syariah lebih tahan dibandingkan konvensional saat menghadapi krisis keuangan global tahap pertama (2007-2009), karena perbankan syariah tidak berinvestasi pada produk-produk keuangan beracun. 
Menteri Perdagangan dan Industri Singapura yang juga menjabat Ketua Otoritas Moneter Singapura, Lim Hang Kiang juga mengatakan bank syariah semakin luas diterima dan memiliki daya tarik sebagai investasi yang lebih etis, menjadikan industri ini tumbuh dua kali lipat dibandingkan dengan konvensional. Walaupun beberapa waktu lalu sempat mengalami penurunan akibat krisis keuangan global, namun popularitas bank syariah terus menanjak, sehingga secara umum outlook keuangan syariah tetap positif (Arif, 2010).

Perkembangan yang pesat dari perbankan syariah menuntut adanya pengawasan. Dewan komisaris dalam kapasitasnya sebagai pengawas operasi perusahaan bertindak sekaligus sebagai pengawas dan memperhatikan kepentingan stakeholders. Untuk melaksanakan perannya sebagai pengawas, dewan komisaris dapat menggunakan jasa penasehat profesional yang mandiri dan/atau membentuk komite khusus. Salah satu komite khusus yang dapat dibentuk dewan komisaris adalah komite audit. Dewan komisaris wajib membentuk komite audit yang beranggotakan satu atau lebih anggota dewan komisaris independen. Dewan komisaris dapat meminta kalangan luar perusahaan dari berbagai keahlian, pengalaman dan kualifikasi lain yang dibutuhkan, untuk duduk sebagai anggota komite audit guna mencapai tujuan peran komite audit (Komite Nasional Kebijakan Corporate Governance, 2000). Efektifitas komite audit dalam memantau proses pelaporan keuangan diteliti oleh Klein (2002); Felo, Krishnamurthy, \& Solieri (2003); Xie, Davidson, \& DaDalt (2003); Abbott et al. (2004); Bédard, Chtourou(2004); Persons (2005); Lin, Li \& Yang (2006); Qin (2007); dan Archambeault, DeZoort, \& Hermanson (2008). Mereka menemukan bahwa terdapat keterkaitan antara karakteristik komite audit dengan kualitas pelaporan keuangan.

Peran lain dari komite audit diungkapkan oleh Elbanon (2009) yang menyatakan efektifitas dari komite audit yang merupakan salah satu mekanisme corporate governance adalah untuk meningkatkan efektifitas pengendalian intern atas pelaporan keuangan. Pendapat Elbanon didukung oleh Teamnuay dan Sapleton (2009) yang membagi peran komite audit atas peran dalam hubungannya dengan 1) audit eksternal; 2) audit internal; 3) pelaporan keuangan eksternal; 4) fungsi lainnya; 5) kualitas pelaporan keuangan.

Deputi Gubernur Bank Indonesia Halim Alamsyah pada tanggal 22 Juni 2011 menyatakan bank di Indonesia harus belajar dari kasus Barings Bank dan Enron. Barings Bank merupakan salah satu bank tertua di London, Inggris. Namun bank tersebut akhirnya kolaps pada tahun 1995, setelah menderita kerugian hingga US\$ 1,3 miliar akibat investasi spekulatif yang dilakukan karyawannya pada kontrak berjangka. Dijelaskan Halim, kasus Barings Bank itu terjadi karena tidak adanya pembagian tanggung jawab yang merata, lemahnya pengawasan internal dan kurangnya pengawasan top manajemen. Kasus yang terjadi di luar negeri juga terjadi di Indonesia. Di Indonesia sedikit banyaknya yang terjadi adalah belum dilakukannya pelaksanaan SOP dan pengawasan internal secara baik. Selain itu kurangnya pengawasan puncak atau top manajemen. Halim selanjutnya mengatakan, pengawasan puncak sudah dilakukan namun tidak jarang prosedur yang sifatnya umum dan sederhana 
justru banyak ditemukan tidak dilaksanakan secara reguler. Enron Corporation adalah sebuah perusahaan energi Amerika yang berbasis di Houston, Texas, Amerika Serikat. Enron menjadi sorotan masyarakat luas pada akhir 2001, ketika terungkapnya unsur penipuan akuntansi yang sistematis, terlembaga, dan direncanakan secara kreatif dalam pelaporan keuangan (Purnomo, 2011).

Di Indonesia terjadi beberapa kasus perbankan yang merugikan nasabah maupun pemerintah dalam jumlah besar sejak tahun 1990. Kasus ini melanda hampir semua bank karena masalah kurangnya pengawasan. Jos Luhukay, pengamat Perbankan dari Strategic Indonesia dalam diskusi "Kejahatan Perbankan" pada hari Senin (2/5/2011), menyatakan adanya beberapa kasus perbankan yang terjadi akhir-akhir ini menjadi pelajaran bagi industri perbankan agar tidak mengalami hal yang sama. Modus kejahatan perbankan bukan hanya soal penipuan (fraud), tetapi lemahnya pengawasan internal control bank terhadap sumber daya manusia juga menjadi titik celah kejahatan perbankan. Internal control menjadi masalah utama perbankan. Untuk mengatasi ini Bank Indonesia harus mengatur standard operating procedure (Dwiantika, $2 \mathrm{Mei}$ 2011).Senada dengan Josh Lukuhay, dalam infobanknews.com pada hari Senin tanggal 2 Mei 2011, pengamat perbankan Paul Sutaryono juga mengharapkan agar pengawasan lebih ditingkatkan. Dengan pengawasan yang ketat, kejahatan bisa diminimalisir sehingga kepentingan investor dan nasabah terlindung (Sutaryono, 2011).

Direktur utama PT Bank Rakyat Indonesia Syariah, Ventje Rahardjo,dalam wawancara dengan harian Bisnis Indonesia pada tanggal 17 April 2011 mengatakan bank syariah memanfaatkan momentum skandal pembobolan dana nasabah untuk meningkatkan kontrol internal nasabah meskipun sebagian besar kasus tersebut terjadi pada bank konvesional. Menurut Bareskrim Mabes Polri sebagian besar kasus tersebut melibatkan pihak internal bank yang bersangkutan(Banjarnahor, 2011).

Terjadinya masalah penting terkait sistem akuntansi keuangan dan pelaporan yang mengakibatkan kebangkrutan perusahaan besar, seperti: Enron, WorldCom dan Global Crossing pada awal abad 21, membuat dunia bisnis menyadari pentingnya kualitas pelaporan keuangan (Kintzele, 2008). Kebangkrutan tersebut karena masalah pelaporan keuangan (Fogarty, 2009). Robinson dan Munter (2004) mengungkapkan, berdasarkan survey yang dilakukan pada manajer portfolio dan analis sekuritas oleh Association for Investment Management and Research (AIMR), ditemukan bahwa kualitas pelaporan keuangan sangat penting sekali (43\%), sangat penting $(30 \%)$ dan agak penting (22\%) bagi pemakai.

Banyak peneliti yang telah mengemukakan konsep kualitas pelaporan keuangan. Miller dan Bahnson (1999) mengemukakan kualitas perusahaan keuangan diproksikan dengan pengungkapan informasi yang lengkap, tepat waktu dan dapat dipahami. Jonas dan Blanchet (2000:360) menyatakan kualitas pelaporan dilihat dari tercapainya kerangka kerja konseptual. Ia mengungkapkan kerangka kerja untuk menilai kualitas pelaporan keuangan, meliputi: 1) Relevance/ earning persistence; 2) Relevance/earning persistence; 3) Relevance/feedback 
value; 4) Timeliness; 5) Verifiability; 6) Completeness; 7) Representation Faithfulness; 8) Neutrality; 9) Comparability; 10) Consistency; dan 11) Clarity. Salah satu cara mengukur kualitas pelaporan keuangan adalah dengan memperhatikan ada/tidaknya masalah pengakuan pendapatan (George dan Philips, 2001). Sedangkan Broadley (2007) menyimpulkan hasil diskusi dari Hundred Group of Finance Directors bahwa kualitas pelaporan keuangan diukur dari terpenuhinya delapan faktor berikut: 1) tujuan laporan keuangan, 2) kerangka kerja pelaporan keuangan, 3) standar akuntansi, 4) konvergensi, 5) pelaporan kinerja, 6) dasar pengukuran, 7) narrative reporting and supplemental information, 8) forward looking information. Beberapa ahli akuntansi Islam dengan berpedoman pada Al Qur'an dan Hadist menyatakan kerangka kerja pelaporan keuangan meliputi: 1) Timeliness, 2) Verifiability, 3) Completeness, 4) Comparability, 5) Consistency, 6) Representational Faithfulness, 7) Neutrality dan 8) Clarity (Syahatah, 2001;Lewis, 2001, 2006; Zaid, 2004; Isgiyarta, 2010).

Berikut ini disajikan kasus-kasus terkait kualitas pelaporan keuangan yang terjadi di Indonesia maupun di dunia.

Tabel 1. Kasus Perbankan terkait masalah Pelaporan Keuangan

\begin{tabular}{|l|l|}
\hline No. & \multicolumn{1}{|c|}{ Kasus } \\
\hline 1. & $\begin{array}{l}\text { Bank Syariah Mandiri (BSM) dan BNI Divisi Usaha Syariah bahkan ikut } \\
\text { dalam kredit sindikasi proyek Indosat Multimedia Mobil (IM3) dan } \\
\text { memperoleh bunga atas pembiayaan tersebut 19\% per tahun. Bank syariah } \\
\text { tidak boleh memakai konsep bunga, sehingga keuntungan pembiayaan ini } \\
\text { tidak boleh dilaporkan dalam laporan laba rugi. }\end{array}$ \\
\hline 2. & $\begin{array}{l}\text { Islamic Bank of South Africa bangkrut pada November 1997 dengan hutang } \\
\text { antara R50-R70 juta, ini terjadi karena buruknya manajemen serta sistem } \\
\text { akuntansi dan manajemen yang tidak tepat, yaitu pinjaman tanpa agunan } \\
\text { pihak intern dalam jumlah besar menyebabkan besarnya kredit macet di } \\
\text { neraca. }\end{array}$ \\
\hline 3. & $\begin{array}{l}\text { Dubai Islamic Bank mengalami kecurangan mendekati US\$300 juta pada } \\
\text { tahun 1998. Hal initerjadi karena buruknya pelaporan keuangan bank. }\end{array}$ \\
\hline 4. & $\begin{array}{l}\text { Bank Takwa dan Islamic Money Management Companies di Mesir bangkrut, } \\
\text { padahal sebelumnya laporan keuangannya tidak bermasalah. }\end{array}$ \\
\hline 5. & $\begin{array}{l}\text { Belum lengkapnya penyajian laporan keuangan oleh bank syariah di } \\
\text { Indonesia. Beberapa bank tidak menyajikan laporan sumber dan penggunaan } \\
\text { dana kebajikan dan laporan sumber dan penggunaan zakat. }\end{array}$ \\
\hline
\end{tabular}

Sumber: Diolah dari Agustianto (2008) dan Rajhi \& Hasairi (2011) serta annual report bank syariah di Indonesia.

Kasus - kasus perusahaan yang menunjukkan pentingnya internal control dan pengawasan tidak hanya terjadi di Indonesia. Di Amerika Serikat akibat gelombang kegagalan bisnis dan skandal korporasi yang dimulai dengan kasus Enron pada tahun 2001, kongres Amerika Serikat mengeluarkan SarbanesOxley Act (SOX) pada bulan Juli 2002. Tujuan SOX adalah memperkenalkan reformasi tata kelola perusahaan yang bertujuan untuk merestorasi kepercayaan investor terhadap pasar modal. SOX membentuk Public Company Accounting Oversight Board yang disingkat PCAOB (Agami, 2006:32). Section 404 dari 
SOX yang dikeluarkan bulan Juni 2003 mengharuskan manajemen untuk menilai efektifitas internal control over financial reporting (ICOFR) dan mewajibkan auditor independen untuk melaporkan penilaian manajemen dan efektifitas internal control over financial reporting perusahaan (Deloitte \& Touche LLP et al., 2004).

Pengendalian intern atas pelaporan keuangan yang efektif adalah penting untuk pencatatan transaksi yang tepat dan penyiapan laporan keuangan yang andal. Suatu proses pengendalian intern yang efektif harus komprehensif dan melibatkan orang-orang pada semua level di perusahaan (Deloitte \& Touche LLP et al., 2004). Pentingnya pengendalian intern dan kebutuhan akan pengendalian intern yang efektif dapat membantu untuk memastikan operasional perusahaan dan tujuan keuangan terpenuhi selamanya (Kinney, 2001; Kinney, Maher \& Wright, 1990).

Untuk memastikan bank syariah sesuai dengan syariah, setiap bank harus mempunyai dewan pengawas syariah (Karim, 1990b; Abdallah, 1994; Briston dan El-Ashker, 1986). Karim (1990b) berpendapat dewan pengawas syariah juga terlibat dalam kebijakan akuntansi. Ini didukung oleh Abdallah (1994) yang menyatakan dewan pengawas syariah bertanggung jawab untuk menjalankan audit ex ante dan ex post untuk menjustifikasi sejauh mana operasi bank syariah sesuai dengan syariah.

Perbedaan karakteristik bank syariah dan bank konvensional kemungkinan besar mempengaruhi praktek pelaporan keuangan (Naser dan Pendlebury, 1997). Operasional bank syariah yang harus sesuai aturan Islam berimplikasi pada pelaporan keuangan (Tomkins dan Karim, 1987). Bank Islam harus menjamin semua transaksinya mematuhi syariah, tidak hanya secara formal dan legal, tetapi juga yang lebih penting substansi sosial ekonomi yang berdasarkan tujuan syariah (Dusuki, 2008). Karenanya keberadaan DPS untuk memberikan opini terhadap tingkat kepatuhan institusi pada aturan syariah (Alexakis, dan Tsikouras, 2009). Accounting and Auditing Organization for Islamic Financial Institution mengharuskan dewan pengawas syariah dan auditor keuangan dari bank syariah untuk melaporkan kepatuhan dengan aturan syariah (AAOIFI, 2004). Standar AAOIFI secara eksplisit menyatakan dewan pengawas syariah dimaksudkan untuk menginvestigasi kesesuaian bank syariah dengan prinsip dan aturan syariah dalam semua aktivitasnya. Investigasi termasuk pemeriksaan memorandum bank dan aturan dari asosiasi, kontrakkontrak, laporan keuangan dan berbagai laporan lainnya (Bakar, 2002). Karim (1995) menekankan otoritas dewan pengawas syariah sama dengan auditor eksternal.

Laporan keuangan adalah sumber informasi yang dipercaya para pemakai laporan keuangan untuk mengetahui kinerja manajemen dan posisi keuangan perusahaan. Pada bank syariah yang salah satu konsepnya adalah bagi hasil, laporan keuangan mempunyai peranan yang penting. Agar dapat memberikan bagi hasil yang tepat pada nasabah pendanaan maupun menerima bagi hasil dari nasabah pembiayaan, dibutuhkan laporan keuangan yang berkualitas. Untuk menghasilkan laporan keuangan yang berkualitas dibutuhkan pelaporan 
keuangan yang berkualitas. Ini juga harus ditopang oleh pengendalian intern atas pelaporan keuangan yang berkualitas (Deloitte \& Touche LLP et al., 2004).Laporan keuangan yang berkualitas adalah yang sesuai dengan prinsip akuntansi berlaku umum dan memenuhi aturan yang ada dan DPS menjamin kredibilitas laporan keuangan (Karim, 1993).Tujuan pelaporan keuangan syariah adalah untuk menentukan zakat (Baydoun dan Willet, 2000). DPS mempunyai tiga tugas yaitu ex ante auditing, ex post auditing dan menentukan zakat (Brishton \& El Ashker, 1986). Sehingga DPS terhadap kualitas pelaporan keuangan syariah.

Berdasarkan fenomena yang dipaparkan di atas, maka dapat dirumuskan tema sentral penelitian ini, yaitu: kualitas pelaporan keuangan bank syariah diduga akan dapat tercapai dengan baik apabila dilaksanakan pengendalian intern atas pelaporan keuangan yang efektif. Pelaksanaan pengendalian intern atas pelaporan keuangan yang efektif memerlukan penerapan peran dewan pengawas syariah dan komite audit. Oleh karena itu, diperlukan suatu penelitian untuk menguji secara empirik atas dugaan tersebut dengan judul "Pengaruh Penerapan Peran Komite Audit, Peran Dewan Pengawas Syariah dan Efektifitas Pengendalian Intern atas Pelaporan Keuangan terhadap Kualitas Pelaporan Keuangan Bank Syariah".

\section{TUJUAN PENELITIAN}

Tujuan yang hendak dicapai dalam penelitian ini adalah untuk memperoleh bukti empiris tentang:

1. Kuatnya hubungan antara peran komite audit denganperan dewan pengawas syariah.

2. Kuatnya hubungan antaraperan komite audit denganefektifitas pengendalian intern atas pelaporan keuangan.

3. Kuatnya hubungan antaraperan dewan pengawas syariah denganefektifitas pengendalian intern atas pelaporan keuangan.

4. Besarnya pengaruh peran komite audit dan dewan pengawas syariah terhadap efektifitas pengendalian intern atas pelaporan keuangan serta implikasinya terhadap kualitas pelaporan keuangan pada bank syariah baik secara simultan maupun parsial.

\section{METODE}

\subsection{METODE PENELITIAN YANG DIGUNAKAN}

Metode penelitian yang digunakan dalam penelitian ini adalah metode survey dengan pendekatan metode verifikatif. Tipe hubungan penelitian ini adalah penelitian kausal, karena meneliti hubungan antar variabel yang diteliti dan untuk mengetahui pengaruh satu atau lebih variabel terhadap variabel lainnya. 


\subsection{OPERASIONALISASI VARIABEL}

Operasionalisasi variabel dari penelitian ini sebagai berikut: Peran Komite Audit (KA) terdiri dari dimensi peran terkait pengendalian intern dan peran terkait pelaporan keuangan; Peran Dewan Pengawas syariah (DPS) terdiri dari dimensi pengawasan terhadap produk baru dan pengawasan terhadap kegiatan bank; Efektifitas pengendalian intern atas pelaporan keuangan (PI) terdiri dari dimensi pengendalian preventif dan pengendalian deteksi; kualitas pelaporan keuangan (KP) terdiri dari dimensi: ketepatanwaktu, dapat diverifikasi, kelengkapan, penyajian secara jujur, netralitas, komparabilitas, konsistensi, dan kejelasan.

\subsection{POPULASI DAN TEKNIK PENGAMBILAN SAMPEL}

Populasi sasaran dalam penelitian ini adalah bank syariah di Indonesia, baik yang berbentuk bank umum syariah maupun unit usaha syariah. Berdasarkan Statistik Perbankan Syariah yang dikeluarkan Bank Indonesiaper Juli 2011 terdapat 11 bank umum syariah dan 23 unit usaha syariah.

Unit analisis pada penelitian ini adalah bank syariah, sedangkan unit observasi adalah anggota komite audit, anggota dewan pengawas syariah, group head, division head atau staf yang berhubungan dengan topik penelitian. Jawaban dari responden kemudian dirata-ratakan per kelompok bank.

\section{HASIL DAN PEMBAHASAN}

\subsection{HUBUNGAN ANTARA PERAN KOMITE AUDIT, PERAN DEWAN PENGAWAS SYARIAH DAN EFEKTIFITAS PENGENDALIAN INTERN ATAS PELAPORAN}

$$
\text { KEUANGAN. }
$$

Dalam analisis jalur, diuji korelasi antar variabel independen. Berikut ini Tabel 2 yang menjelaskan Correlations untuk uji sub struktural.

Tabel 2. Correlations

\begin{tabular}{|ll|r|r|r|}
\hline & & \multicolumn{1}{|c|}{ PI } & \multicolumn{1}{c|}{ KA } & \multicolumn{1}{c|}{ DPS } \\
\hline Pearson Correlation & PI & 1.000 & .602 & .857 \\
& KA & .602 & 1.000 & .668 \\
& DPS & .857 & .668 & 1.000 \\
\hline Sig. (1-tailed) & PI & .000 & .000 & .000 \\
& KA & .000 &. & .000 \\
& DPS & .000 & .000 & \\
\hline $\mathrm{N}$ & PI & 33 & 33 & 33 \\
& KA & 33 & 33 & 33 \\
& DPS & 33 & 33 & 33 \\
\hline
\end{tabular}

Sumber: Data primer yang diolah

Dewan Pengawas Syariah dengan efektifitas pengendalian intern yang memiliki hubungan sangat kuat karena korelasi diatas 0,8 (Riduwan dan Kuncoro, 2007) karena pada bank syariah masyarakat lebih melihat pelaksanaan kepatuhan 
syariah dibanding kinerja keuangannya (Dusuki, 2001). Sedangkan hubungan antar variable lainnya termasuk kategori kuat karena korelasi antara $0,6-0,8$.

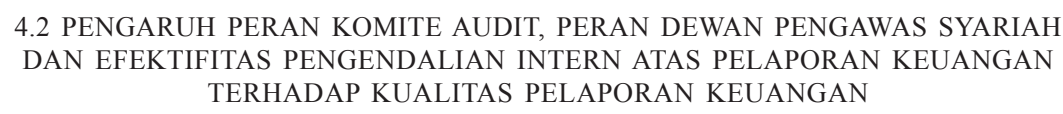

\subsubsection{Hasil Uji Secara Simultan}

Berikut ini Tabel 3 yang menjelaskan Anova untuk uji secara simultan pengaruh Peran Komite Audit (KA), Peran Dewan Pengawas Syariah (DPS), dan Efektifitas Pengendalian Intern atas Pelaporan Keuangan (PI) terhadap Kualitas Pelaporan Keuangan (KP).

Tabel 3. Annova

\begin{tabular}{|c|c|c|c|c|c|c|}
\hline \multicolumn{2}{|c|}{ Model } & Sum of Squares & Df & Mean Square & $\mathrm{F}$ & Sig. \\
\hline \multicolumn{2}{|c|}{ Peorecsion } & \multirow{3}{*}{$\begin{array}{r}3286.769 \\
283.959 \\
3570.727\end{array}$} & \multirow{3}{*}{$\begin{array}{r}3 \\
29 \\
32\end{array}$} & \multirow{3}{*}{$\begin{array}{r}1095.590 \\
9.792\end{array}$} & \multirow[t]{3}{*}{111.890} & \multirow[t]{3}{*}{.000} \\
\hline & Residual & & & & & \\
\hline & & & & & & \\
\hline
\end{tabular}

b. Dependent Variable: KP

Dari tabel 3 karena nilai sig $<0,05$, maka keputusannya adalah Ho ditolak dan Ha diterima, artinya koefisien analisis jalur adalah signifikan. Dalam penelitian ini berarti secara simultan terdapat pengaruh Peran Komite Audit, Peran Dewan Pengawas Syariah, dan Efektifitas Pengendalian Intern atas Pelaporan Keuangan terhadap Kualitas Pelaporan Keuangan.

Untuk mengetahui besarnya pengaruh komite audit, Dewan Pengawas Syariah dan Efektifitas pengendalian intern atas pelaporan keuangan secara gabungan dapat dilihat dari hasil penghitungan dalam model summary, khususnya angka $\mathrm{R}_{\text {square. }}$ Tabel 4 yang menjelaskan Summary untuk analisis jalur.

Tabel 4 Model Summary

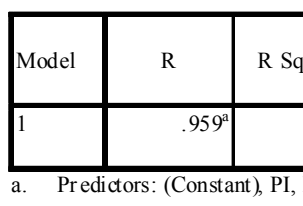

Dari Tabel 4 besarnya angka $\mathrm{R}_{\text {square }}\left(\mathrm{r}^{2}\right)$ adalah 0,920 . Angka tersebut mempunyai maksud bahwa penerapan peran komite audit, Dewan pengawas Syariah dan Efektifitas pengendalian intern atas pelaporan keuangansecara bersama terhadap kualitas pelaporan keuangan bank syariah adalah 92,0\%. Adapun sisanya sebesar 8,0\% (100\% - 92,0\%) dipengaruhi oleh variabel lain.

\subsubsection{Hasil Uji Secara Parsial}

Berikut ini Tabel 4.21 yang menjelaskan coefficients untuk uji secara parsial pengaruh Peran Komite Audit (KA), Peran Dewan Pengawas Syariah (DPS), 
dan Efektifitas Pengendalian Intern atas Pelaporan Keuangan (PI) terhadap Kualitas Pelaporan Keuangan (KP).

Tabel 5. Coefficients

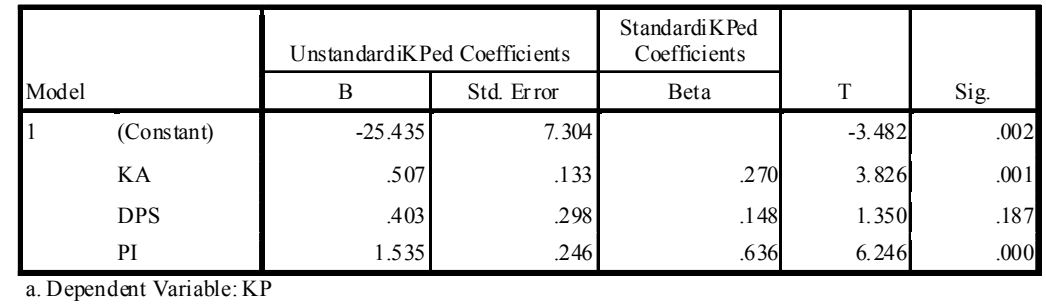

Dari tabel diatas, semua variabel secara parsial peran komite audit dan efektifitas pengendalian intern atas pelaporan keuangan berpengaruh terhadap kualitas pelaporan keuangan karena nilai $\operatorname{sig}<0,05$. Untuk variabel peran dewan pengawas syariah secara statistik tidak signifikan.

Berdasarkan hasil dari koefisien jalur, maka dapat digambarkan secara keseluruhan yang menggambarkan hubungan kausal empiris antar variabel KA, DPS dan PI terhadap KP sebagai berikut.

Gambar 1. Hubungan Kausal Empiris Variabel KA, DPS dan PI terhadap KP

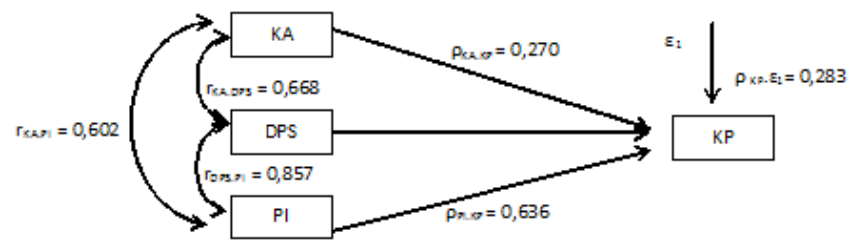

\section{SIMPULAN DAN SARAN}

\subsection{SIMPULAN}

Simpulan dari hasil penelitian adalah sebagai berikut:

1. Terdapat hubungan antara Peran Komite Audit, Peran Dewan Pengawas Syariah dan Efektifitas Pengendalian Intern atas Pelaporan Keuangan.

2. Peran Dewan Pengawas Syariah dan Efektifitas Pengendalian Intern atas Pelaporan Keuangan memiliki hubungan yang paling kuat.

3. Peran Komite Audit, Peran Dewan Pengawas Syariah dan Efektifitas Pengendalian Intern atas Pelaporan Keuangan berpengaruh secara simultan terhadap Kualitas Pelaporan Keuangan.

4. Secara partial Peran Komite Audit, dan Efektifitas Pengendalian Intern atas Pelaporan Keuangan berpengaruh signifikan terhadap Kualitas Pelaporan Keuangan, namun secara statistic Peran Dewan Pengawas Syariah tidak signifikan. 


\subsection{SARAN}

Berdasarkan kesimpulan hasil penelitian yang telah dikemukakan, maka saransaran yang diajukan adalah sebagai berikut:

5.2.1 Saran Pengembangan Ilmu

1) Bagi dunia akademis, hasil penelitian ini diharapkan dapat menjadi masukan yang berharga dalam mempelajari teori-teori yang berhubungan dengan efektifitas pengendalian intern atas pelaporan keuangan dan kualitas pelaporan keuangan.

2) Penelitian ini belum mengungkapkan seluruh variabel yang berhubungan dengan efektifitas pengendalian intern atas pelaporan keuangan dan kualitas pelaporan keuangan, maka dalam rangka penelitian lanjutan diharapkan meneliti variabel lain seperti peran auditor internal, komitmen manajemen, dan corporate governance.

3) Bagi peneliti berikutnya, untuki variabel efektifitas pengendalian intern atas pelaporan keuangan dapat menggunakan proksi material weaknesses, sedangkan untuk variabel kualitas pelaporan keuangan dapat menggunakan proksi kualitas pelaporan keuangan tinggi, rendah dan sangat rendah.

\subsubsection{Saran Operasional}

Alternatif pemecahan masalah belum besarnya peran komite audit terhadap efektifitas pengendalian intern atas pelaporan keuangan pada bank syariah adalah dengan: (1) mereview kelayakan sistem pengendalian intern; (2) meminta keterangan tentang perubahan kebijakan akuntansi; serta 3) mereview pengungkapan dalam laporan segmen.

Sedangkan bagi dewan pengawas syariah agar berperan lebih aktif dalam kualitas pelaporan keuangan dengan 1) mereview sistem dan prosedur produk baru yang akan dikeluarkan;2) menetapkan jumlah uji petik (sampel) transaksi yang akan diperiksa; dan 3) memeriksa sampel dokumen transaksi.

Belum berpengaruhnya peran dewan pengawas syariah terhadap kualitas pelaporan keuangan dapat diatas dengan tidak adanya perangkapan jabatan dan manajemen bank harus menambah karyawan yang mendukung pelaksanaan tugas dewan pengawas syariah.

\subsection{KETERBATASAN}

1. Belum lengkapnya laporan keuangan maupun laporan tahunan bank umum syariah dan unit usaha syariah yang dipublikasikan di website perusahaan. Ketika diminta langsung ke manajemen perusahaan, beberapa tidak bersedia memberikannya.

2. Banyak item-item pengungkapan yang belum dicantumkan perusahaan dalam laporan keuangan maupun laporan tahunannya.

\section{DAFTAR PUSTAKA}

AAOIFI. 2004. Accounting and Auditing Standards for Islamic Financial Institutions. Manama, Bahrain: AAOIFI. 
Agami, Abdel M. 2006. Reporting on Internal Control over Financial Reporting. The CPA Journal, November, 76, 11:32-34.

Agustianto. 2008a. Optimalisasi Dewan Pengawas Syariah. www.niriah.com diakses tanggal

Antonio, Muhammmad Syafii. 2001. Bank Syariah: Dari Teori ke Praktek. Jakarta: Gema Insani Press.

Archambeault, D.S., Dezoort, F.T. and Hermanson, D.R. 2008. Audit Committee Incentive Compensation and Accounting Restatements. Contemporary Accounting Research, Vol.25, No.4: 965-92.

Arif, Johar. Perbankan Syariah Indonesia Urutan Keempat di Dunia. www.republika.co.id 11 November 2011 diakses tanggal 18 maret 2011.

Banjarnahor, Donald. 2011. BRI Syariah Tingkatkan Pengawasan Internal. Harian Bisnis Indonesia tanggal 17 April 2011. http://www.bisnis.com/finansial/ perbankan/20433-bri-syariah-tingkatkan-pengawasan-internal. Diakses tanggal 5 Mei 2011.

Briston, R. \& El-Ashker, A. 1986. Religious Audit: Could It Happen Here? Accountancy, October: 120-1.

Chapra, U.M\& Ahmed, H. 2002. Corporate Governance in Islamic Financial Institutions. Occasional Paper No. 6. Jeddah: Islamic Research and Training Institute, Islamic Development Bank.

Chapra, M. Umer \& Thariqullah Khan . 2000. Regulation and supervision of Islamic bank Occasional paper No.3. Jeddah: Islamic Development Bank \& Islamic Research and Training Institute

Deloitte \& Touche LLP et al. 2004. Internal Control over Financial Reporting: an Investor Resources.

DeZoort, F. Todd dan Steven E. Salterio. 2001. The Effect of Corporate Governance Experience, Financial Reporting and Audit Knowledge on Audit Committee Members' Judgments. Auditing A Journal of Practice \& Theory, Vol. 20, No. 2 .

Dusuki, Asyraf Wajdi. 2008. Understanding the Objectives Islamic Banking: A Survey of Stakeholders' perspectives. International Journal of Islamic and Middle Eastern Finance and Management, Vol. 1, No. 2: 132-148.

Dwiantika, Nina. Inilah 9 kasus kejahatan perbankan di kuartal I 2011. Artikel. Kontan. 2 Mei 2011. http://keuangan.kontan.co.id/news/inilah-9-kasus- 
kejahatan-perbankan-di-kuartal-i-2011-1. Diakses tanggal 3 Mei 2011.

Felo, A., Krishnamurthy, S. and Solieri, S. 2003. Audit committee characteristics and the perceived quality of financial reporting: an empirical analysis.Working paper. Pennsylvania State University, SUNY at Binghamton and University of Scranton.

George, Moriarty dan Philib B. Livingston. 2001. Quantitative measure of the Quality of Financial Reporting. Financial Executive. Jul/Agus, Vol.17, No.5,pp.53-56.

Isgiyarta, Jaka. 2010. Teori Akuntansi dan Laporan Keuangan Islami. Semarang: Badan Penerbit Universitas Diponegoro.

Jonas, Gregory J dan Jeannot Blanchet. 2000. Assessing Quality of Financial Reporting. Accounting Horizons, Sep; 14,3; Pg. 353

Karim, R. A. A. 1990a. Standard Setting for the Financial Reporting of Religious Business Organizations: The Case of Islamic Banks. Accouting and Business Research, Vol.20, No.80, pp.299-305.

. 1990b. The Indepence of Religious \& External Auditors: the case of Islamic Banks. Auditing, Accounting and Accountability Journal. Vol.3, No.3, pp.34-44.

Kinney, W. 2000. Research Opportunities in Internal Control Quality and Quality Assurance. Auditing, 19, 83-90.

Lewis, Mervyn K. 2001. Islam and Accounting. Accounting Forum Vol.25 No.2: 103-127.

Miller, Paul B dan Paul R. Bahnson. 1999. Quality Financial Reporting: Why You Need It and How to Implement It. The Journal of Corporate Accounting and Finance, Vol.11, No.1: 83-101.

Persons. O. S. 2005. The Relation Between the New Corporate Governance Rules and the Likelihood of Financial Statement Fraud. Revewof Accounting \& Finance, Vol.4, No.2: 125-148.

Purnomo, Herdaru. 2011. Pembobolan bank di RI Mirip-Mirip Kasus Pembobolan Beken di Dunia. Artikel. 22 Juni 2011. http://finance.detik.com/read/2011/ 06/22/115753/1665876/5/pembobolan-bank-di-ri-mirip-mirip-kasuspembobolan-beken-di-dunia. Diakses tanggal 3 Juni 2012.

Sutaryono, Paul. 2011. Saatnya Pengawasan Bank menjadi Panglima. http:// www.infobanknews.com/2011/05/saatnya-pengawasan-bank-menjadi- 
panglima/. Diakses tanggal 5 Mei 2011.

Syahatah, Husein. 2001. Pokok-pokok Pikiran Akuntansi Islam. Terjemahan Husnul Fatarib. Jakarta: Akbar

Tomkins, Cyril \&Rif'at Ahmed Abdul Karim. 1987. The Shari'a and Its Implications for Financial Analysis: An Oppurtunity to Study Interactions between Society, Organizations and Society. The American Journal of Islamic Social Sciences, September, Vol.4: 101-15

Zaid, Omar Abdullah. 2004. Akuntansi Syariah: Kerangka Dasar dan Sejarah Keuangan dalam Masyarakat Islam. Terjemahan M. Syafii Antonio \& Sofyan Syafri Harahap. Jakarta: LPFE Universitas Trisakti. 